\title{
A Invenção de um Dispositivo como Suplência à Metáfora Paterna: efetuar a torção da superfície unilateral
}

\author{
LInvention $d$ un Dispositif comme Suppléance au défaut de la \\ Métaphore Paternelle: effectuer la torsion de l unilatère \\ The Invention of a Device as Substitute in the Absence of the Paternal \\ Metaphor: achieving the torsion of the unilateral surface
}

http://dx.doi.org/10.5007/2178-4582.2013v47n2p362

Fabienne Hulak

Université de Paris VIII, Paris, France

Tradução de Leticia Vier Machado

Universidade Federal de Santa Catarina, Florianópolis/SC, Brasil

\begin{abstract}
O conceito lacaniano de sinthome como suplência à forclusão do Nome-do-Pai permite reconhecer na clínica uma categoria distinta daquela do delírio como reconstrução imaginária do mundo. Apresentamos três casos que se aparecem sob este novo paradigma clínico. Cada um apresenta uma variante da torção topológica da superfície unilateral que vem suprir a carência daquela efetuada pela metáfora paterna, condição do inconsciente ao qual o psicótico não tem acesso.
\end{abstract}

Palavras-chave: anamorfose clínica lacaniana - psicose - R. Roussel - F. Saussure - suplência
Le concept lacanien de sinthome, comme suppléance à la forclusion du Nom-du-Père, permet de repérer dans la clinique une catégorie distincte de celle de délire comme reconstruction imaginaire du monde. Nous présentons trois cas relevant de ce nouveau paradigme clinique. Chacun présente une variante de la torsion topologique de l unilatère qui supplée à la carence de celle effectuée par la métaphore paternelle, condition de linconscient auquel le psychotique $n$ a pas accès.

Mots clés: Anamorphose, clinique lacanienne, psychose, $R$. Roussel, F. Saussure, suppléance
The lacanian concept of sinthome as a substitute for the forcluded Name-of-the-Father, allows the recognition in the clinic of a category distinct from delirium as an imaginary reconstruction of the world. We present three cases that come under this new clinical paradigm. Each one exposes a variant of the topological torsion of the unilateral surface that comes in place of $s$ the one effected by the paternal metaphor, condition of the unconscious to which the psychotic does not have access.

Keywords: anamorphose - Lacanian clinic - psychose, R. Roussel, F. Saussure, replacement

Apresentaremos três casos na perspectiva da invenção de um dispositivo que visa fazer suplência ao que Lacan denominou forclusão do significante do Nome-do-Pai, ou seja, à carência da metáfora paterna. Trata-se de dois sujeitos historicamente notáveis, Ferdinand de Saussure e Raymond Roussel, e do Senhor L., um caso relevante do mesmo paradigma. É certo que cada um deles se situa em seu espaço cultural próprio : Saussure, com uma invenção de caráter científico no domínio da linguística, estará na origem da teoria do estruturalismo que terá repercussões em vários outros campos, Raymond Roussel com uma obra literária e poética que será primeiramente reconhecida pelos surrealistas e depois pelo movimento l Oulipo, Tel quel. O Senhor L., 
um caso singular que demonstra um esforço formidável para construir um dispositivo plástico que adquire para ele valor terapêutico. Veremos como cada um, à sua maneira, efetua a torção topológica que o sustenta enquanto sujeito. Dito de outra maneira, o dispositivo procurado por alguns criadores consiste em construir a torção da superfície unilateral equivalente àquela do insconsciente ao qual eles não têm acesso. É o que procuraremos mostrar.

\section{A pesquisa sobre os anagramas}

A julgar pela quantidade de seus cadernos, Ferdinand de Saussure certamente consagrou um tempo considerável a sua pesquisa sobre os anagramas ${ }^{1}$. Como ressalta J. Starobinski em sua apresentação da publicação parcial dos manuscritos « a quantidade de trabalho permanece (...) impressionante $\rangle^{2}$ (STAROBINSKI, 1971, p.7). Entretanto, apesar de sua importância, essa pesquisa passou despercebida na história e na teoria da linguística.

O trabalho deste linguista sobre « Os anagramas » se apoia inicialmente sobre um corpus restrito, aquele do verso saturnino, a forma mais antiga da poesia latina, da qual restaria menos de uma centena de versos, assim catalogados pela tradição dos gramáticos antigos. Os versos saturninos são caracterizados por sua dimensão enigmática e assim já o eram na época da Roma imperial. É sem dúvida essa característica que constitui o atrativo para Saussure.

Saussure queria postular de maneira precisa que os poetas gregos e latinos compunham seus versos partindo de uma palavra tema cujos fonemas deveriam ser utilizados de acordo com determinadas regras. Supõe que todo verso saturnino contém em si um nome escondido sob forma de anagrama e empreende a decifragem e a análise fônica desse tipo de verso a fim de encontrar o nome secreto contido no texto latino, produto de um saber escondido.

\section{A busca do significante no anagrama : o nome ou locus princeps}

De 1906 à 1909 o anagrama é o objeto agalmático do desejo de Saussure. Ele parte então da intuição segundo a qual existiria no verso saturnino um nome escondido que daria uma forma pré-limitada ao verso e que existiria um texto sob/no texto, o anagrama.

Saussure extrai uma lei que presidiria à organização do poema : os elementos fônicos que aparecerem em cada verso do poema são repetições ordenadas do material sonoro de uma palavra tema. Na maioria das vezes essa palavra está em relação com o título ou com o assunto tratado, devendo os fragmentos da palavra-tema aparecerem o mais frequentemente possível. É a este fenômeno que ele dá o nome de anagrama ; ele distingue também o hipograma, uma forma especial de anagrama.

${ }^{1}$ O curso de linguística geral é ministrado por Saussure entre 1907 e 1911. Ele seria então, em grande parte, posterior à pesquisa sobre os anagramas que se estende de 1906 a 1909.

${ }^{2}$ No original : « la somme de travail reste (...) impressionnante » (STAROBINSKI, 1971, p.7) 
Ele mostra que o funcionamento do procedimento anagramático é construído a partir do " manequim » (" mannequin ») que é uma sequência de palavras « comprimida e delimitável » ${ }^{3}$ (STAROBINSKI, 1971, p. 50) na qual os fonemas, inicial e final, são os mesmos que na palavra tema. Essa sequência de palavras ou « complexo-manequim » (« complexe-mannequin ») constitui o centro do verso anagramático e ajuda a adivinhar a palavra tema, que é, na maioria das vezes, um nome próprio. O complexo-manequim é o elemento central organizador do anagrama que condensa em um lugar do verso os fonemas do nome crucial que Saussure denomina lugar soberano ou «locus princeps » (Ibid., p. 50).

Esse lugar é simultaneamente interior e exterior à cadeia significante, visto que é ele que organiza o verso. O nome anagramático, afirma J.C. Milner, « não é nada mais que o verso ele-mesmo, considerado como sequência de fonemas, concentrado em um ponto : o Um do nome encarnado, o Um que governa o verso, como um verso e como divisível em elementos discerníveis, um a $u m \gg^{4}$ (MILNER, 1978, p. 90-91). Esse nome escondido no texto é, portanto, o que o produz. Ele é o significante mestre que organiza a cadeia significante, [...] É « o significante Um do ' há Um na cadeia significante' incluído na cadeia significante $»^{5}$ (Ibid.).

\section{Loucura filológica}

A hipótese dos anagramas não tem nada de inverossímil sob a perspectiva do método filológico que se apoia sobre a gramática comparada. Esta considera que uma língua única, a indo-europeia, está na origem das homofonias entre as diversas línguas. É uma língua inteiramente construída pela notação das arborescências « em uma escrita regrada e limitada $\square$ pelas leis fonéticas $»^{6}$ (MILNER, 1978, p. 109). É « a matriz e a escrita de todos os equívocos ».

Nesse sentido, o indo-europeu é para cada língua o significante-mestre encarnado. Ou, como ressalta J.C. Milner, visto que a etmologia ilustrada de Bloch e Von Wartburg se refere a datações absolutas e a provas documentais, a etmologia indo-europeia diz respeito somente a precedências relativas e provas estruturais. Além disso, J.C. Milner ressalta que os próprios indoeuropeanistas suspeitam que sua disciplina tangencia a loucura, estando o saber do indoeuropeanista $《$ infectado por um desejo $»^{7}$ (Ibid, p. 108).

Encontramos assim esse ponto de subjetivação do método filológico em Saussure, que se manifesta e se focaliza particularmente nessa pesquisa do nome anagramático que ele extrai do verso saturnino e do qual esse nome seria a causa.

\footnotetext{
${ }^{3}$ No original: \serrée et delimitable $\square$ (STAROBINSKI, 1971, p. 50)

${ }^{4}$ No original: «n'est rien d'autre que le vers lui-même, considéré en tant que suite de phonèmes, concentré en un point : le Un du nom incarnant le Un qui gouverne le vers, en tant que $u n$ vers et en tant que divisible en éléments discernables, un à un » (MILNER, 1978, p. 90-91).

${ }^{5}$ No original: « le signifiant Un du 'il y a de l'Un dans la chaîne signifiante' inclus dans la chaîne signifiante » (Ibid.).

${ }^{6}$ No original: « dans une écriture réglée et contrainte - par les lois phonétiques » (MILNER, 1978, p. 109).

${ }^{7}$ No original: « infecté d'un désir » (Ibid, p. 108).
} 
Saussure descobre um primeiro princípio no verso saturnino : « os fonemas de cada tipo estão sempre em número par » o que implica em « somente o número dos fonemas é limitado, mas não sua natureza. [...] em um verso saturnino, os fonemas são escolhidos a partir de um nome, ligado de modo crucial ao sentido narrativo do verso $»^{8}$ (Ibid., p. 88).

Uma vez provado esse princípio, o verso não pode mais ser remetido ao aleatório, e podemos então supor-lhe uma causa específica: um saber, que repousaria sobre um segredo; hipótese verossímil sob o ângulo da filologia, ela mesma sustentada por um mito. Temos aí, afirma J.C. Milner, « uma língua que é inteiramente elocubração de saber $»^{9}$ (Ibid., p.108).

Contudo, a prova deveria poder ser obtida mostrando que existem textos sem anagramas e que todos os anagramas encontrados são efeito de uma técnica específica. Mas Saussure acaba por perceber anagramas em todos os textos... e se encontra então « em presença de um real incontornável... do qual a filologia não poderia fazer nada [...] $\gg^{10}($ MILNER, 1978, p. 88-89).

\section{O cristal da língua : lalangue}

Saussure está então envolvido com o cristal da língua mas também com o árduo problema que consiste em falar da própria língua. Está confrontado a esse cristal que repousa sobre o equívoco e a homonímia. É o que Lacan nomeia "lalangue » " dito de outra maneira, isso pelo que, de um único e mesmo movimento, há a língua (ou seres qualificáveis de falantes [...]) e há o inconsciente $\gg^{11}$ (Ibid., p. 26).

$\mathrm{Na}$ língua há uma dimensão do não-idêntico : «é o equívoco e tudo o que dele deriva, homofonia, homografia, tudo o que suporta a ambiguidade (...) $\rangle^{12}$ (Ibid.,p.18). «Pois vemos bem que uma locução, trabalhada pelo equívoco, é simultaneamente ela mesma e uma outra. Sua unicidade se refracta seguindo séries que escapam à decomposição, visto que cada uma, apenas nomeada significação, sonoridade, escrita, etmologia, sintaxe, calembur... - se refracta por sua vez indefinidamente (...) $»^{13}$ (Ibid.).

Por outro lado, há na linguagem a dimensão de uma elocubração de saber que estratifica lalangue em la langue.

\footnotetext{
${ }^{8}$ No original: « les phonèmes de chaque type sont toujours en nombre pair » ce qui implique que « seul donc le nombre des phonèmes est contraint, mais non pas leur nature. [...] dans un vers saturnien, les phonèmes sont choisis à partir d'un nom, lié de manière cruciale au sens narratif du vers » (Ibid., p. 88).

${ }^{9}$ No original: « une langue qui est toute entière élucubration de savoir » (Ibid., p.108).

${ }^{10}$ No original: « en présence d'un réel incontournable... dont la philologie ne pouvait rien faire [...] » (MILNER, 1978, p. 88-89).

${ }^{11}$ No original: « autrement dit, ce par quoi, d'un seul et même mouvement, il y a de la langue (ou des êtres qualifiables de parlants [...] ) et il y a de l'inconscient» (Ibid., p. 26).

${ }^{12}$ No original: «c'est l'équivoque et tout ce qui en relève, homophonie, homographie, tout ce qui supporte la double entente (...)» (Ibid.,p.18)

${ }^{13}$ No original : « Car on voit bien qu'une locution, travaillée par l'équivoque, est à la fois elle-même et une autre. Son unicité se réfracte suivant des séries qui échappent au décompte, puisque chacune, à peine nommée - signification, sonorité, écriture, étymologie, syntaxe, calembour... -, se réfracte à son tour indéfiniment (...)» (Ibid.).
} 
Saussure se encontra então em contato direto com a matéria fugaz de lalangue ; ele é confrontado a ela por sua pesquisa sobre a gramática comparada, seus estudos sobre a lenda e os anagramas aos quais ele dedica um imenso interesse.

\section{O sintoma de Saussure : o anagrama e a proliferação do nome}

O sintoma de Saussure se situa nessa pesquisa que se torna invasiva. A amplitude de suas pesquisas sobre o nome próprio adquire diferentes formas, dentre as quais aquela dos estudos sobre a lenda que mostra que ele é polarizado pelo significante do Nome-do-Pai ${ }^{14}$, imantado pela questão do pai, problemática para ele.

Saussure constata que encontra por toda parte esse « fonismo dirigido a um nome e procurando a reprodução desse nome $\gg^{15}$ (MILNER, 1978, p. 61). O nome escondido é, na maioria das vezes, um nome próprio (aquele de um deus ou de um herói) (Ibid., p. 28), funcionando então o verso saturnino como epitáfio. Como veremos, o nome encontrado faria assim a função, de Nomedo-Pai no texto fúnebre.

$\mathrm{O}$ anagrama é um significante-mestre e na medida em que esse nome secreto organiza a cadeira significante em relação à qual ele está em posição de exterioridade, é um substituto (ersatz) do Nome-do-Pai, conceito formulado por Lacan que faz do pai uma metáfora, uma formalização que visa substituir o fundamento mítico do complexo de Édipo por um fundamento literal. Com efeito, para que se desenvolva no inconsciente a cadeia significante, é preciso que exista um significante exterior que lhe permita se articular, fazer ponto de capitonê $\hat{e}^{16}$. É este significante particular, organizador que é denominado por Lacan de Nome-do-Pai (LACAN, 1981).

Para alguns o Nome-do-Pai falhará e nesse caso há a forclusão (Verwerfung), ou seja, a recusa desse significante primordial (Ibid., p. 71). Encontramo-nos então no registro da psicose.

\section{Defender-se de lalangue}

Nos textos estudados por Saussure proliferam os anagramas e seu trabalho, no início delimitado, deriva ao infinito, aplicando-se a todos os versos, todas as épocas, todos os textos... A busca compulsiva do anagrama pode então ser comparada a uma interpretação delirante que se impõe no texto do poema, variante do retorno no Real do significante do Nome-do-Pai.

\footnotetext{
${ }^{14}$ Termo que em Lacan designa um puro significante da métafora paterna.

${ }^{15}$ No original: « phonisme dirigé sur un nom et cherchant la reproduction de ce nom » (MILNER, 1978, p. 61)

${ }^{16} \mathrm{O}$ ponto de capitonê liga o significante ao significado. Mas há também certo número de pontos de capitonê em toda a cadeia significante. Esses pontos permitem a articulação de uma unidade significante (frase), a possibilidade da emergência de uma significação daí decorrente. Na definição dada por Lacan, o Nome-do-Pai é o significante a partir do qual se opera a articulação de toda a cadeia significante no inconsciente : o ponto de capitonê. Cf. Lacan J, O seminário, livro III, As psicoses.
} 
A interpretação delirante foi objeto, em 1921, de um notável estudo realizado por Paul Guiraud, intitulado « As formas verbais da interpretação delirante » (GUIRAUD, 1921). Ele ressalta que « de todas as construções delirantes, aquelas baseadas sobre interpretações se aproximam mais do modo normal do pensamento ; elas podem até se elaborar em um sistema suficientemente verossímil $\gg^{17}$ (Ibid., p. 395).

Dentre as diversas variedades de interpretações delirantes distinguidas por P. Guiraud aquela dos raciocínios por jogos de palavras (raisonnements par jeux de mots) parece ser a que mais corresponde ao funcionamento de Saussure. P. Guiraud constata que "Os raciocínios por jogos de palavras » constituem a forma mais frequente de interpretação verbal. " A semelhança de duas palavras basta para estabelecer (...) uma ligação real entre duas ideias e adquire valor de prova. Às vezes a palavra é decomposta em fragmentos que por aproximação com palavras consonantes dão uma explicação mórbida da palavra inicial $\gg^{18}$ (Ibid., p. 401). Todavia, alguns casos procedem essencialmente por homonímias ou jogos de palavras apoiados sobre os nomes próprios. Encontramos assim no estudo de P. Guiraud o caso do Senhor M. que decompõe os nomes próprios e atribui a eles uma significação relacionada ao seu delírio os quais ele diz serem « etimologias » (Ibid., p. 405).

P. Guiraud distingue ainda as interpretações com ou sem justificativa lógica da sua forma mais extrema, a interpretação delirante que chega à « afirmação puramente afetiva ». O calembur está no espaço entre o delírio e o fenômeno alucinatório como para o Senhor M., que interpreta celulóide : é Lulu que a enviou pelo Loyd (celluloïd : c eest Loulou qui l a envoyé par le Lloyd...)

Remetendo-nos ao estudo de Guiraud podemos considerar que Saussure teria encontrado uma verossimilhança para sua atividade interpretativa porque ela era motivada por aquela dos filólogos.

Saussure se encontra às voltas com « o saber inconsciente da língua mesma $»^{19}$ (MILNER, 1978, p. 89) escreve J.C. Milner em seu livro «O amor da língua » («L amour de la langue ») no qual ele nos apresenta sua leitura da obra de Saussure : « um linguista desejante ».

O saber inconsciente da língua faz referência implícita à formulação segundo a qual « uma língua, entre outras, não é nada mais do que o total dos equívocos que sua história deixou persistir $»^{20}$ (LACAN, 1973, p. 47) o que Lacan nomeia utilizando o termo, que diz ser « saussuriano », de « lalangue » (Id. 1971) e que escreve doravante em uma só palavra.

${ }^{17}$ No original : «Les formes verbales de linterprétation délirante » (GUIRAUD, 1921). « de toutes les constructions délirantes, celles qui sont basées sur des interprétations se rapprochent le plus du mode normal de la pensée ; elles peuvent même s'élaborer en un système assez vraisemblable» (Ibid., p. 395).

${ }^{18}$ No original: « La similitude de deux mots suffit à établir (...) un lien réel entre deux idées et prend la valeur d'une preuve. Tantôt le mot est décomposé en fragments qui par rapprochement avec des mots consonnants donnent une explication morbide du mot initial» (Ibid., p. 401).

${ }^{19}$ No original : « le savoir inconscient de la langue elle-même » (MILNER, 1978, p. 89).

${ }^{20}$ No original : « une langue, entre autres, n'est rien de plus que l'intégrale des équivoques que son histoire y a laissé persister » (LACAN, 1973, p. 47). 
Parece que a partir do desenvolvimento proliferante da interpretação, Saussure pôde se contrapor a esse fenômeno.

Com efeito, ele não está na certeza delirante, ele precisa da garantia do Outro e quer ter no exterior a confirmação da realidade de suas descobertas. $\mathrm{Na}$ incerteza quanto aos resultados de seus estudos, ele escreve à Giovanni Pascoli ${ }^{21}$, professor e poeta italiano seu contemporâneo, cujos poemas são pastiches da mais pura poesia latina. Ele pergunta à Pascoli se este tinha, ele mesmo, utilizado conscientemente o procedimento do " hipograma ».

Tullio de Mauro 22 , apresentador da edição crítica do Curso de Linguística Geral em 1972, considerará que é o silêncio de G. Pascoli que teria impulsionado Saussure a dar fim a suas pesquisas ${ }^{23}$. Esse silêncio teria the permitido frear o que poderia ter se tornado uma invasão.

É desse saber inconsciente da língua, ela mesma, lalangue, veículo do retorno no Real do significante do Nome-do-Pai forcluído, que Saussure deverá se defender pela formulação do algorítmo significado/significante, no fundamento de sua linguística.

Com efeito, formulamos a hipótese que Saussure teria sido " desabonado do inconsciente » (LACAN, 2005), expressão utilizada por Lacan a propósito de Joyce. Parece que a partir da interrupção da pesquisa sintomática dos anagramas, Saussure teria sido compelido a abstrair, a estabelecer sua elaboração teórica. Ela deu origem à invenção da linguística estrutural. Após ter contido o Imaginário, que nele estava ameaçado de transbordar na prática dos anagramas, eliminou o sentido de toda frase pela invenção do algoritmo que diferencia o significado e o significante a partir de uma descrição de caráter topológico : «A língua é também comparável a uma folha de papel : o pensamento é o anverso e o som, o verso ; não se pode cortar um sem cortar, ao mesmo tempo, o outro; assim tampouco, na língua, se poderia isolar o som do pensamento, ou o pensamento do som (...) » ${ }^{24}$ (SAUSSURE, 1972, p. 157).

Com essa formalização, Saussure se distancia do sentido que proliferava nos anagramas para se aproximar da mais pura literalidade. Ele opera um salto a partir de um sistema que poderia igualmente ter-se desenvolvido de uma interpretação delirante e chega ao seu sinthome : uma invenção de caráter científico, a linguística estrutural que terá uma influência considerável, muito além de seu campo.

Lembremos que o termo sinthome designa em sua origem a função específica que teve a escrita para o escritor J. Joyce. Lacan tenderá a generalizar o uso desse termo para designar a suplência que reestabelece o nó

${ }^{21}$ Professor titular da cadeira de literatura italiana na Universidade de Bologna.

${ }^{22}$ Linguista e apresentador geral do Curso de linguística geral de Saussure.

${ }^{23}$ Mauro T., Rossi (1968), Starobinski S., Arrivé M.(2007), parecem estar de acordo sobre esse ponto.

${ }^{24}$ No original: « La langue est encore comparable à une feuille de papier : la pensée est le recto et le son le verso ; on ne peut découper le recto sans découper en même temps le verso; de même dans la langue, on ne saurait isoler ni le son de la pensée, ni la pensée du son (...) » (SAUSSURE, 1972, p. 157). Versão em português : SAUSSURE, F. Curso de linguística geral. 27 ed. São Paulo : Cultrix, 2006. p. 131. 
borromeano dos três registros - Real, Simbólico e Imaginário -, necessário à constituição do sujeito. Como Saussure fez essa passagem do sintoma no sentido psiquiátrico ao sinthome?

É pela produção de seu algoritmo que a pesquisa de Saussure vai adquirir o caráter de um sinthome na medida em que essa invenção, em razão de seu nível de abstração literal análoga ao « termo de uma operação matemática ${ }^{25}$ (SAUSSURE, 1972, p. 302), barra a deriva interpretativa.

$\mathrm{O}$ fato de enunciar seu algoritmo como primeiro princípio, a arbitrariedade do signo (ou seja, seu caráter imotivado), permitiu a Saussure colocar um basta à fuga da interpretação na busca de uma origem, de uma causalidade que o conduzia a uma deriva delirante. A partir daí, ele poderá construir todo seu sistema.

\section{A invenção de um Nome-do-Pai : a arbitrariedade do signo}

Segundo J.C. Milner, Saussure construiu « um modelo do signo que se desvincula de toda teoria da representação » (MILNER, 2002, p. 28). A linguística não é mais uma visão do mundo e « a ligação que a unia desde os gregos à teoria do ser das coisas é rompida » ${ }^{26}$ (Id., 1978, p. 59).

Saussure postula a arbitrariedade do signo. A relação entre o significado e o significante é arbitrária e imotivada. O encontro entre o signo e a coisa significada é então contingente, sua necessidade é orientada de outra maneira. O signo linguístico saussuriano é « negativo, (...), opositivo e relativo » (Ibid, p. 60) e à diferença do signo dos filósofos, « o signo saussuriano não representa : ele representa para os outros signos (...). $\|^{27}$ (Ibid., p. 60).

$O$ princípio da arbitrariedade do signo supõe que « o signo não deve ter outro mestre que não ele mesmo, e não é mestre de outro que não dele mesmo » ${ }^{28}$ (Ibid., p. 8). Ele adquire então para nós valor análogo ao Nomedo-Pai.

\section{A torção da superfície unilateral, suplência à falta da metáfora}

Lacan inverte os termos do algoritmo (significante/significado) porque a barra saussuriana implica do lado do significado a elisão de um segundo significante. Isso que ele expressa com a fórmula da metáfora paterna (LACAN, 1966) : o primeiro significante (o Nome-do-Pai) encontrando-se no lugar do desejo da mãe, situado abaixo. O desejo da mãe ele mesmo reconduzido, acima da barra no lugar de um x enigmático.

\footnotetext{
${ }^{25}$ (index 2121, coluna 5).

${ }^{26}$ No original : « un modèle du signe qui se disjoint de toute théorie de la représentation » (MILNER, 2002,p. 28). « le lien qui l'unissait depuis les Grecs à la théorie de l'être des choses est rompu » (Id., 1978, p. 59).

${ }^{27}$ No original : « le signe saussurien ne représente pas : il représente pour les autres signes (...). » (Ibid., p. 60).

${ }^{28}$ No original : « le signe ne doit avoir d'autre maître que lui-même, et n'est maître que de lui-même » (Ibid., p.8).
} 


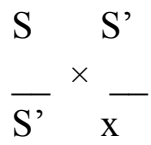

Nome-do-Pai

Desejo da Mãe

\author{
Desejo da Mãe \\ Significado ao sujeito
}

J. Granon-Lafont (1990) mostra que essa operação de substituição da metáfora paterna, de um lado e de outro da barra saussuriana, é de fato a expressão de uma torção moebiana. Ela esclarece a imagem da folha de papel evocada por Saussure na divisão do significante e do significado. Essa relação de um primeiro significante a um segundo, elidida, fornece ao algoritmo a dimensão de uma operação subjetiva : " o significante representa o sujeito para outro significante », assim como assinala J.C. Milner, o conceito de signo em Saussure não conduz a nada além dele mesmo. Não há sujeito. J.C. Milner ressalta também que o signo é paradoxal ; « o elemento que deve assegurar o discernimento, é atravessado pela multiplicidade das oposições nas quais ele é tomado ; não há substância que assegure a instância do Um. É que o signo se ajusta a um silêncio : ele é construído de maneira que o sujeito seja forcluído (...) $»^{29}$ (MILNER, 1978, p. 87).

Adotamos a hipótese de que para Saussure o significante do Nome-doPai fora forcluído e que assim ele fora « desabonado » da estrutura de linguagem do inconsciente. Podemos conjecturar que graças a sua invenção de uma função literal que se conformaria ao discurso da ciência, ele teria suprido a carência simbólica da função do Nome-do-Pai.

Podemos deduzir que o algoritmo permitiu encontrar a fórmula da metáfora e efetuar uma torção topológica. Essa torção é o que é suprido na forclusão do Nome-do-Pai. Podemos assim nos apoiar na perspectiva de uma colocação em série da função dessa torção como procedimento de suplência à falta da função do inconsciente em um sujeito assim « desabonado » pela forclusão do Nome-do-Pai.

Vimos que o verso saturnino se insere em uma perspectiva filológica na qual Saussure desenvolve uma metodologia fundada sobre uma certa racionalidade científica. Isso não impede que seja um sintoma que ameaçava tornar-se delirante. Com a formulação da arbitrariedade do signo, afastando-se da questão da origem, ele pode fundar seu sistema e passar propriamente ao nível de uma elaboração de seu sinthome. Ele formula a própria estrutura da metáfora e aquela da torção topológica da superfície unilateral.

Com Raymond Roussel entramos em outra perspectiva, a de uma invenção literária que se aproxima de um protocolo de experiência científica.

${ }^{29}$ No original: « l'élément même qui doit assurer le discernement, est traversé par la multiplicité des oppositions où il est pris ; il n'a pas de subsistance qui assure l'instance de l'Un. C'est que le signe s'ajuste à un silence : il est construit en sorte que soit forclos le sujet (...)» (MILNER, 1978 p. 87). 


\section{A invenção do procedimento : desdobrar a cadeia significante}

Roussel não é um poeta inspirado (CARADEC, 1997, p. 358) e vai, ao contrário, se empenhar em construir um protocolo de escrita : o procedimento, que ele deseja oferecer aos futuros escritores.

Ele se sente obrigado a escrever, por uma imperiosa necessidade interna, mas ainda precisa elaborar seu dispositivo, que deverá suprir para ele a carência da metáfora paterna a qual está, lembremo-nos, no fundamento da estrutura da metáfora.

Para poder escrever, ele se impõe restrições que, no entanto, na leitura nos dão a impressão de uma grande liberdade no interior de um enquadre deliberadamente construído. Isso não ocorre sem obstáculos e lhe é necessário um tempo considerável para escrever um único verso. Aliás, ele registra a dificuldade experienciada : ele « sangra a cada frase $»^{30}$ (ROUSSEL, 1963a, p. 125).

Roussel fabrica então enunciados que excluem a espontaneidade da enunciação. Ele os passa pela sua pequena máquina lógica que lhe permite construir um mundo engendrado a partir de frases agenciadas segundo certas regras previamente escolhidas.

Ele confessa ao poeta Robert Desnos que consagra a cada dia quinze horas de trabalho para a escrita de um único verso e que levou doze anos para escrever as Novas Impressões da África (Nouvelles Impressions $d \square$ Afrique) ! (ROUSSEL, 2004). Nada de menos inspirado então que seu trabalho, um duro labor. Além disso, faz cálculos complexos para contabilizar o tempo que passou escrevendo. Ele se considera um descobridor de procedimentos regulados a partir de dados objetivos e se posiciona de boa vontade ao lado do discurso da ciência. Esses procedimentos adentram uma problemática literal e semântica e seu trabalho se aparenta àquele de um lógico : produzir escritos, enunciados a partir de frases ready-made, "insignificantes " (endereços retirados de sua caderneta, legendas de desenhos humorísticos, publicidades, canções de infância, ou ainda fragmentos de suas obras anteriores, etc.).

Roussel indica assim que sua prática de escrita consiste em uma « resolução de (...) problema(s) » (ROUSSEL, 1963a, p. 12), « eu escolhia duas palavras quase iguais (remetendo aos metagramas). Por exemplo billard e pillard. Em seguida eu acrescentava palavras iguais mas tomadas em dois sentidos diferentes, e obtinha assim duas frases quase idênticas. (...) As duas frases encontradas, tratava-se de escrever um conto, podendo começar pela primeira e terminar pela segunda. Era da resolução desse problema que eu tirava todos meus materiais $»^{31}$ (Ibid., p. 11-12).

\footnotetext{
${ }^{30}$ No original: « saigne sur chaque phrase » (ROUSSEL, 1963a, p. 125).

${ }^{31}$ No original : « je choisissais deux mots presque semblables (faisant penser aux métagrammes).Par exemple billard et pillard.. Puis j'y ajoutais des mots pareils mais pris dans deux sens différents, et j'obtenais ainsi deux phrases presque identiques. (...) Les deux phrases trouvées, il s'agissait d'écrire un conte pouvant commencer par la première et finir par la seconde. Or c'était dans la résolution de ce problème que je puisais tous mes matériaux » (Ibid., p. 11-12).
} 
Isso produz por exemplo essas duas frases :

« $1^{\circ}$ ) Les lettres $d u$ blanc sur les bandes $d u$ vieux billard...

$2^{\circ}$ ) Les lettres du blanc sur les bandes du vieux pillard ». : $\mathbf{b} / \mathbf{p}$.

Na primeira, « lettres » eram tomadas no sentido de « signos tipográficos » (letras) , «branco » no sentido de « cubo de giz » e « bandas » no sentido de « bordas ». Na segunda, "lettres » eram tomadas no sentido de « missivas » $(\text { cartas })^{32}$, « branco » no sentido de « homem branco » $\mathrm{e}$ « bandas » no sentido de « hordas guerreiras ».

É portanto por um deslizamento literal do $b$ ao $p$ que ele obtém o movimento, a torção de um campo semântico a outro. A operação se fez aqui pelo entreposto de uma só letra, um movimento de torção que conduz a uma disjunção do sentido.

A fim de poder escrever, Roussel deve passar pela homofonia e por uma translação: é o princípio gerador de seus mundos imaginários. O procedimento estimula o ato da escrita que lhe fazia obstáculo.

De acordo com F. Caradec, biógrafo de Roussel, os procedimentos são « procedimentos de escrita ». " Não são procedimentos de leitura : não é absolutamente necessário para o leitor conhecê-los ; ao contrário, pois eles podem lentificar ou interromper sua leitura $\|^{33}$ (CARADEC, 1997, p. 70). Parecem-nos, ao contrário, suscitar e estimular a posição do leitor enquanto pesquisador ! F. Caradec considera que o procedimento é um método para construir « pequenos jogos de palavras $»^{34}$ (Ibid., p. 69), Roussel diz « ter encontrado [sua] via pelas combinações de palavras ». Contudo, veremos que, contrariamente ao algoritmo de Saussure, o procedimento não resiste à dificuldade causada pelos nomes próprios.

O procedimento " clássico » contém três fases de fabricação : busca de calemburs ou de frases com duplo sentido (às vezes holorímicos ${ }^{35}$ ), estabelecimento de uma trama lógica unindo esses elementos díspares, e redação tão realista quanto possível, com um máximo de rigor, do texto definitivo.

Segundo Roussel « esse procedimento, em suma, é parente da rima ». É a maneira que ele encontrou para fazer « vir » a prosa, já que os versos vinham a ele mais facilmente : « sua orelha musical encontra-se sem dúvida satisfeita por revelar em sua própria prosa os contrapontos de seu procedimento sem recorrer ao eco das rimas $»^{36}$ (CARADEC, 1997, p. 70). Saussure afirma : «é pela Aliteração que cheguei à chave do saturnino $»^{37}$ (ROUSSEL, 2005, p. 21).

${ }^{32}$ Em francês, $\square$ ettres $\square$ pode designar $\square$ letras $\square$ ou $\llbracket$ cartas $\square$ (N.T.)

${ }^{33}$ No original : «procédés d'écriture ». « Ce ne sont pas des procédés de lecture : il n'est pas du tout nécessaire pour le lecteur de les connaître ; au contraire même, car ils peuvent ralentir ou arrêter sa lecture » (CARADEC, 1997, p. $70)$.

${ }^{34}$ No original : « de petits pièges-à-mots » (Ibid., p. 69).

${ }^{35}$ Os versos holorímicos são versos foneticamente parecidos.

${ }^{36}$ No original: « ce procédé, en somme, est parent de la rime », « son oreille musicienne est sans doute satisfaite de déceler dans sa propre prose les contrepoints de son procédé sans avoir recours à l'écho des rimes » (CARADEC, 1997 p. 70).

${ }^{37}$ No original: « c'est par l'Allitération que je suis arrivé à tenir la clef du saturnien » (ROUSSEL, 2005, p. 21). 
Roussel registra ainda que o procedimento evolui. Ele explica : « eu escolhia uma palavra e então a religava a outra pela preposição $a$; e essas duas palavras, tomadas em outro sentido que não o sentido primitivo, forneciam-me uma nova criação (...) $»^{38}$ (Id., 1963a, p. 13-14).

« Eu tomava a palavra palmier e decidia considerá-la em dois sentidos : o sentido de doce ${ }^{39}$ e no sentido de árvore. Considerando-a no sentido de doce, eu procurava casá-la com a preposição à com outra palavra suscetível de ser compreendida em dois sentidos diferentes ; eu obtinha assim (e aí, eu repito, era um grande e longo trabalho) um palmier [doce] à restauration [restaurante] (restaurante onde serve-se doces); o que também produzia um palmier [árvore] à restauration [restauração] (sentido de reestabelecimento de uma dinastia sobre um trono). Daí o palmier da praça dos Troféis consagrado à restauração da dinastia dos Talou ${ }^{40}$ (Ibid., p. 14).

«O procedimento evoluira e eu fora conduzido a tomar uma frase qualquer, da qual eu extraía imagens deslocando-a, um pouco como se se tratara de extrair desenhos de charadas.

Tomo um exemplo, aquele do conto Le Poète et la Mauresque $\square(. .$.$) . Aí fiz$ uso da canção ' $J$ ai du bon tabac $\square$.

O primeiro verso : J Jai du bon tabac dans ma tabatière $\square$ me deu : Jade tube onde aubade en mat (objet mat) a basse tierce $\square$ Reconheceremos nessa última frase todos os elementos do conto.» ${ }^{41}$ (Ibid., p. 20).

Existe então um desdobramento da cadeia significante pelo viés da homofonia. Contudo, o procedimento possui uma fraqueza. Ele é colocado em dificuldade quando deve produzir nomes próprios, pois o nome próprio permanece em geral idêntico em todas as línguas e em sua função, ele não tem significação, ele designa.

\section{O problema do nome próprio : um branco no texto}

Se os nomes próprios multiplicam-se em Saussure e se encontram em todos os textos que ele estuda, fazem muita falta a Roussel que encontra grande dificuldade em achá-los.

${ }^{38}$ No original: « Je choisissais un mot puis le reliais à un autre par la préposition à ; et à ces deux mots, pris dans un sens autre que le sens primitif, me fournissaient une création nouvelle (...)» (Id., 1963a, p. 13-14).

${ }^{39}$ Nota da tradução :Palmier é o nome em francês de um doce conhecido no Brasil como « orelha de macaco »e também palmeira

${ }^{40}$ No original: « Je prenais le mot palmier et décidais de le considérer dans deux sens : le sens de gâteau et le sens d'arbre. Le considérant dans le sens de gâteau, je cherchais à le marier par la préposition à avec un autre mot susceptible lui-même d'être pris dans deux sens différents ; j'obtenais ainsi (et c'était là, je le répète, un grand et long travail) un palmier (gâteau) à restauration (restaurant où l'on sert des gâteaux); ce qui donnait d'autre part un palmier (arbre) à restauration (sens de rétablissement d'une dynastie sur un trône). De là le palmier de la place des Trophées consacrée à la restauration de la dynastie des Talou » (Ibid., p. 14)

${ }^{41}$ No original: «Le procédé évolua et je fus conduit à prendre une phrase quelconque, dont je tirais des images en la disloquant, un peu comme s'il se fût agi d'en extraire des dessins de rébus. Je prends un exemple, celui du conte « Le Poète et la Mauresque » (...). Là je me suis servi de la chanson : 'J'ai du bon tabac'. Le premier vers : 'J'ai du bon tabac dans ma tabatière' m'a donné : 'Jade tube onde aubade en mat (objet mat) a basse tierce'. On reconnaîtra dans cette dernière phrase tous les éléments du conte » (Ibid., p. 20). 
Produzir nomes parece altamente problemático para Roussel. Ele conhece bem essa dificuldade, seus textos ficam inacabados por causa dos nomes próprios de seus personagens, que deixa em branco, completanto-os apenas sob pressão, depois que o revisor the tenha sugerido um nome, que ele acaba por mudar no último momento. Assim « Se a escolha dos nomes é tão difícil para ele, parece entretanto que ele a estima muito (...) $\rangle^{42}$ afirma Caradec (1997, p. 114) que constata nesses nomes a presença de homofonias aproximativas ou de anagramas.

Por que Roussel escolhia nomes ou totalmente « inventados », quer dizer, « inteiramente criados e sem nenhuma relação com parônimos possíveis, ou tão bizarros que nos perguntamos quem poderia usá-los $»^{43}$ (Ibid., p. 114) ? O nome próprio torna-se nome comum e encontramos então : «Beffroi », « Débarras », « Boudin », " Givre » entre os nomes inventados... O nome beira a alcunha, o insulto. Lembremos da presença frequente do insulto na alucinação verbal, de propostas que visam o sujeito em seu ser « cadáver »..

Assim, quando Roussel recomenda à Zo, ilustrador das Nouvelles Impressions $d\lceil$ Afrique (ROUSSEL, 2004) desenhar : « Um homem construindo com um ar laborioso uma lista de nomes », ele especifica que « se os nomes estão visíveis, eles devem ser criptografados $! »^{44}$ Saussure decifrava os anagramas, Roussel criptografava seus textos.

\section{Fenômenos de corpo, lapsos da amarração simbólica}

Roussel tem sua primeira grande crise quando escreve seu livro « La doublure ». Ele está então imerso em um sentimento de « glória » e descompensa após a publicação, constatando « que não se retornava sobre sua passagem, o sentimento de glória e a luminosidade se apagaram bruscamente $\rangle^{45}$ (ROUSSEL, 1963a, p. 128).

Esse fenômeno que ele nomeia «a glória »é um gozo intenso pelo qual ele procurará toda a sua vida. Ele está na origem desta « assustadora doença nervosa » de que ele diz ter sofrido por muito tempo e que lhe provocou « uma espécie de doença de pele que se traduzira por uma vermelhidão de todo o corpo $»^{46}$ (Ibid., p. 29).

Sobre este estado ele confessa à P. Janet : « eu sentia a glória... Não, a glória não é uma ideia, uma noção que adquirimos constatando que nosso nome esvoaça sobre as letras dos homens. Não, não se trata do sentimento

\footnotetext{
${ }^{42}$ No original : « Si le choix des noms lui est si difficile, il semble bien cependant qu'il y tienne beaucoup (...) » (CARADEC, 1997, p. 114).

${ }^{43}$ No original : « créés de toutes pièces et sans aucun rapport avec des paronymes possibles, soit si saugrenus que nous nous demandons qui pourrait les porter» (Ibid., p. 114).

${ }^{44}$ No original : « Un homme établissant avec un air laborieux une liste de noms », « si les noms sont visibles, ils doivent être cryptographiés» .

${ }^{45}$ No original : « qu'on ne se retournait pas sur son passage, le sentiment de gloire et la luminosité s'éteignirent brusquement » (ROUSSEL, 1963a, p. 128).

${ }^{46}$ No original: " effroyable maladie nerveuse », " une sorte de maladie de peau qui se traduisit par une rougeur de tout le corps » (Ibid., p. 29).
} 
do próprio valor, do sentimento de que somos merecedores... O que eu escrevia estava cercado por esplendor, eu fechava as cortinas, pois eu tinha medo da menor fresta que tivesse deixado passar para fora os raios luminosos que saíam de minha pluma, eu queria retirar a tela de uma só vez e iluminar o mundo $\gg^{47}$ (Ibid., p. 127).

A glória é uma " sensação » que participa de um estado hipomaníaco que lhe permite não sentir o cansaço, apesar de seu trabalho. É um gozo não falicisado que se apodera do corpo, um gozo Outro, que J.C. Maleval situa na articulação do Real e do Imaginário, sendo a hipótese de que « a glória se produz fora do simbólico $»^{48}$ (MALEVAL, 2003, p. 116) e que isso pode surpreender já que ela parece decorrente de um trabalho de escrita. Entretanto, o próprio Roussel indica que esta não é essencial quando assinala que ela é o que experimentava Napoleão em 1811 ou com o que sonhava Tannhäuser em Venusberg. Roussel especifica que a fonte deslumbrante que não está ligada ao volume não foi criada, pois ele já a carregava consigo. Podemos então considerar que o simbólico não enquadra mais o gozo. Roussel encontra aí a certeza de sua posição de exceção : P. Janet, que cuidou de Roussel, escreve : « Desta crise de glória e de luz, Martia ${ }^{49}$ conservou a convicção inabalável de que teve a glória, de que possui a glória ; que os homens o reconheçam ou não o reconheçam, pouco importa $»^{50}$ (ROUSSEL, 1963a).

J.C. Maleval considera que « a certeza associada de estar em uma situação de exceção, somente comparável à das figuras mais altas, tais como Dante, Shakespeare ou Napoleão, sugere, ao contrário, que a função paterna forcluída retorna no Real $»^{51}$ (MALEVAL, 2003, p. 117). Vários elementos tenderiam a confirmar, sempre segundo J.C. Maleval, que a amarração simbólica com o Real e o Imaginário se mostra falha na estrutura de Roussel. A glória experimentada quando da escrita de seu primeiro romance dá lugar, como aponta Janet, a um severo estado depressivo : « então se iniciara uma verdadeira crise de depressão melancólica com uma forma bizarra de delírio de perseguição, tomando a forma da obsessão e da ideia delirante da denigração universal dos homens uns pelos outros $\rangle^{52}$. Isso faz prova de uma ausência de regulação

${ }^{47}$ No original: « je sentais la gloire... Non, la gloire n'est pas une idée, une notion que l'on acquiert en constatant que votre nom voltige sur les lettres des hommes. Non, il ne s'agit pas du sentiment de sa valeur, du sentiment que l'on mérite ...Ce que j'écrivais était entouré de rayonnement, je fermais les rideaux, car j'avais peur de la moindre fissure qui eût laissé passer au dehors les rayons lumineux qui sortaient de ma plume, je voulais retirer l'écran tout d'un coup et illuminer le monde » (Ibid., p. 127).

${ }^{48}$ No original: « la gloire se produit hors-symbolique » (MALEVAL, 2003, p. 116).

${ }^{49}$ Martial é o nome que dá P. Janet ao caso de de R. Roussel em seu livro Les Caractères Psychologique de lExtase, sem dúvida por causa de um personagem de « Locus solus », Martial Canterel.

${ }^{50}$ No original: « De cette crise de gloire et de lumière, Martial a conservé la conviction inébranlable qu'il a eu la gloire, qu'il possède la gloire ; que les hommes le reconnaissent ou ne le reconnaissent pas, peu importe » (ROUSSEL, 1963a).

${ }^{51}$ No original: « la certitude associée d'être en une situation d'exception, seulement comparable à des figures parmi les plus hautes, telles que Dante, Shakespeare ou Napoléon, suggère en revanche que la fonction paternelle forclose fait retour dans le réel » (MALEVAL, 2003, p. 117).

${ }^{52}$ No original: « (...) alors commença une véritable crise de dépression mélancolique avec une forme bizarre de délire de persécution, prenant la forme de l'obsession et de l'idée délirante du dénigrement universel des hommes les uns par les autres ». 
simbólica do gozo e de uma carência do traço unário. Certo número de sinais clínicos vão nesse sentido, com a temática da doublure ${ }^{53}$, como na imitação perfeita de seu pai, herói de seu livro que é introduzido como duplo. Ele pede que se insira sua foto em todos seus livros após sua morte, inclui a observação clínica que Janet fez do seu caso.

Em Roussel, o Imaginário é tomado com o Real. Assim como ele é às vezes próximo de um estado maníaco, pode ser um parafrênico confabulante quando há o gozo de um Imaginário fantástico. A hipótese é então que, para Roussel, o Simbólico não se sustenta. Essa dimensão, a do simbólico, não assumiria a função de limite para o gozo pois ela não está amarrada de maneira borromeana ao real. Assim, « ainda que o real e o imaginário estejam amarrados, não se opera entre eles aquela conexão que permitiria fixar o simbólico, que fica livre. Contudo Roussel, apesar de alguns momentos depressivos severos, nunca desencadeou uma psicose, o que permite supor que ele chegou a remediar a falha de sua estrutura $\gg^{54}$ (MALEVAL, 2003, p. 120-121). A suplência elaborada pode ser identificada a seu trabalho sobre a escrita. Ele obtém assim, com seu procedimento, um universo de discurso verossímil, que tem a estrutura de ficção. Esse artifício lhe permite uma amarração do imaginário ao simbólico pelo viés da letra.

\section{A flexão do estilo}

Em seu ensaio sobre « Raymond Roussel » M. Foucault (1963) indica que a experiência de Roussel « situa-se no que poderíamos chamar de espaço tropológico do vocabulário ».

« Toda a linguagem de Roussel, estilo invertido, procura dizer subrepticiamente duas coisas com as mesmas palavras. A torção, o leve desvio das palavras que habitualmente lhes permite " deslocarem-se » segundo um movimento tropológico e coloca em jogo sua profunda liberdade, Roussel faz aí um círculo implacável que reconduz as palavras a seu ponto de partida pela força de uma lei coercitiva. A flexão do estilo torna-se sua negação circular » ${ }^{55}$ (Ibid., p. 25).

Foucault aborda o procedimento rousseliano como um tropo. Enquanto podemos reconhecer um leve desvio do sentido das palavras que caracteriza

${ }^{53}$ Nota da tradutora : doubloure refere-se à função ou operação do doublé ou duplo, mais comumente conhecida pelo trabalho dos doublés que emprestam seus corpos para as cenas em que os atores titulares não podem ou não querem utilizar os seus próprios. Ainda que « duplo » seja uma palavra largamente utilizada no vocabulário da psicanálise me Português, doubloure não conta com uma palavra equivalente no nosso idioma.

${ }^{54}$ No original: « bien que le réel et l'imaginaire soient noués, une connexion ne s'opère pas entre eux, celle qui permettrait de coincer le symbolique, lequel de ce fait s'avère libre. Cependant Roussel, malgré quelques moments dépressifs sévères, n'a jamais déclenché une psychose, ce qui laisse supposer qu'il est parvenu à remédier à la défaillance de sa structure " (MALEVAL, 2003, p. 120-121).

${ }^{55}$ No original : « se situe dans ce qu'on pourrait appeler lespace tropologique du vocabulaire ». « Tout le langage de Roussel, style renversé, cherche à dire subrepticement deux choses avec les mêmes mots.La torsion, le léger détour des mots qui d'ordinaire leur permet de 'bouger' selon un mouvement tropologique et de faire jouer leur profonde liberté, Roussel en fait un cercle impitoyable qui reconduit les mots à leur point de départ par la force d'une loi contraignante. La flexion du style devient sa négation circulaire » (Ibid., p. 25). 
um determinado autor, devido à dimensão metafórica do estilo, em Roussel « a flexão do estilo » é de fato a torção efetuada pelo procedimento, que não tem nada de metafórico. É o que Foucault define como a negação circular do estilo. Nesse sentido podemos considerar que Roussel não é um autor.

Assim R. Lew (1985) ressalta que M. Foucault se encontra em posição de passador da obra de Roussel, mas, por outro lado, constata que ele a « apreendeu claramente sem poder (querer ?) articulá-la com uma topologia correta, aquela da superfície unilateral ${ }^{56}$ (Ibid., p. 120). Ele nos oferece, dessa forma, uma « retificação » da leitura feita por Foucault.

Segundo R. Lew « que Roussel o tenha querido ou provavelmente não, que ele o tenha sabido ou seguramente não, sua obra é estritamente moebiana, seu conteúdo, como a própria obra e como a vida de Roussel $\gg^{57}$ (LEW, 1985, p. 120).

\section{A torção}

Com seu procedimento de escrita, Roussel fabrica uma torção que não é, entretanto, aquela do inconsciente. Sobre uma face inscreve um relato e sobre a outra face desenvolve um outro relato. O ponto de conexão é a homofonia sustentada idealmente para ele por uma só letra (cf. seus metagramas).

Jogando com o equívoco, ele constrói um desenvolvimento metonímico no interior de um enquadre : uma separação semântica. Ele descreve o percurso de uma paisagem, uma sucessão sem fim de imagens. Essa torção artificialmente construída supre para ele a necessidade combinatória.

A oscilação, a torção entre um primeiro relato preposto e a prospecção metonímica de um segundo relato constituem uma suplência à sua carência quanto à estrutura metáforica.

Colocando como limite um quase axioma de origem exterior ao desenvolvimento do relato que ele restringe, como Cantor com Aleph, ele pode desenvolver ao infinito seu texto.

Enquanto que, com a abertura metafórica, há um efeito de significação enigmática que relança o desejo jamais satisfeito, em Roussel não é a metáfora que suscita o desejo no leitor, é seu « procedimento » que não se consegue encontrar.

Em suma, em um sujeito dito « desabonado do inconsciente », há a invenção de um sistema que faz função de metáfora.

\section{Da tropologia à topologia}

Roussel, em sua última obra, tentará uma construção moebiana não somente a partir do texto, mas a partir do objeto mesmo do livro.

${ }^{56}$ No original: « a très nettement saisi sans pouvoir (vouloir ?) l'articuler d'une topologie correcte, celle de l'unilatère » (Ibid., p. 120).

${ }^{57}$ No original : « que Roussel l'ai voulu ou probablement pas, qu'il l'ait su ou sûrement non, son oeuvre est strictement moebienne, son contenu comme l'oeuvre même et comme la vie de Roussel » (LEW, 1985, p. 120). 
Em « Nouvelles Impressions d Afrique» de acordo com Y. Pélissier (1999, p. 28) há uma articulação do texto e das imagens, ele aponta que na edição original « somente a frente das páginas está impressa, e que cada página do texto alterna com um desenho, igualmente impresso na frente ». Anteriormente Jean Ferry havia também notado que uma " encadernação engenhosa e inabitual permite ler o livro sem cortá-lo » (Ibid., p. 29). Roussel faz da encadernação um elemento de composição do livro e « de um elemento da encadernação, um elemento do texto mesmo » (Ibid., p. 28). As páginas em si funcionam como parênteses, os desenhos sendo anexados entre " duas folhas não separadas » . Separá-las com um cortador de papel voltaria « a apagar um elemento do texto $»^{58}$ (Ibid., p. 28). Temos portanto uma construção literal que adquire valor de dispositivo escópico, e que adquire uma dimensão topológica tal como o livro total do qual Mallarmé procurava a estrutura.

\section{A imagem anamórfica em Roussel}

E. Leborgne em um estudo literal sobre Roussel, « o procedimento da anamorfose em Les Noces » (PÉLISSIER, 1999), remete o procedimento da anamorfose à definição dada por Alembert na Enciclopédia, assumindo-a como sua.

Essa arte da anamorfose consiste em esconder engenhosamente a « representação 'desfigurada' de uma imagem » o que lhe permite constatar que « fusionar duas imagens diferentes em um único desenho : esse procedimento pode ser conectado ao tema rousseliano da doublure ou do desdobramento [dédoublement] da realidade » (LEBORGNE, 2004, p. 66). Ele observa a partir do exemplo do quadro de $\mathrm{H}$. Holbein « Os embaixadores franceses » (Les ambassadeurs français) (1533) que a anamorfose pode ser em parte ligada à ilusão referencial : " ela é questão do ângulo de visão, mas também, (...) de leitura » (Ibid., p. 67). Há os efeitos de anamorfose mas por outro lado «a segunda etapa da anamorfose refere-se à variação de escala $»{ }^{59}$ (Ibid., p. 72).

E. Leborgne considera, por um lado, que em Les noces, a anamorfose tem lugar de catalisador do imaginário mas também que « a extrema precisão com a qual é descrita a curvatura (courbure) do espaço sobre a superfície convexa dos óculos faz pensar que Roussel, com seu espírito sistemático, está expondo um procedimento completamente poético, cuja origem permanece misteriosa »(LEBORGNE, 2004, p. 74).

Ele se pergunta se existe « uma frase metagramática que nos faria passar do espaço realista de Courbet ao espaço curvado (courbé) de Roussel,

\footnotetext{
${ }^{58}$ No original : « seul le recto des pages est imprimé, et que chaque page du texte alterne avec un dessin, également imprimé au recto ». « brochage ingénieux et inhabituel permet de lire le livre sans le couper» (Ibid., p. 29). « d'un élément de la reliure, un élément même du texte » (Ibid., p. 28). « deux feuillets non disjoints ». « à effacer un élément du texte » (Ibid., p. 28).

${ }^{59}$ No original : « représentation 'défigurée' d'une image », « fusionner deux images différentes en un seul dessin : ce procédé peut être rattaché au thème roussellien de la doublure ou du dédoublement de la réalité » (LEBORGNE, 2004, 66). « elle est affaire d'angle de vision, mais aussi, (...) de lecture » (Ibid., p. 67). « la seconde étape de l'anamorphose porte sur la variation d'échelle» (Ibid., p. 72).
} 
segundo o procedimento linguístico que descreve em seu célebre texto póstumo ? $\gg{ }^{60}$ (Ibid., p. 74).

Com o fragmento retirado de uma página de «Des noces », E. Leborgne afirma que « esse exemplo de anamorfose mostra a maneira pela qual a associação livre de ideias está estritamente calcada no fenômeno da ótica : o pensamento abraça o movimento do olhar que « salta » de um telhado a outro. É a mistura de rigor geométrico e de carnavalização burlesca » (Ibid., p. 74) « traços de escrita » que serão reutilizados nos romances em prosa e que de acordo com ele se dirigem « à elaboração consciente de um Procedimento rousseliano $»^{61}$. Após o abandono de Roussel do poema «Des noces » (ROUSSEL, 1963b) não existiriam mais do que distantes avatares desse procedimento geométrico e em Impressions $d\lceil$ Afrique (Id., 2005 ) encontraremos apenas uma variante estetizada do fenômeno da anamorfose.

Les Noces são um vasto campo experimental de onde emerge uma visão poética « que atinge [...] seu apogeu no momento em que o mundo físico está concentrado em um ponto que conteria simbolicamente todo o espaço, à semelhança do aleph de Borges » (LEBORGNE, 2004, p. 80). Lembremos que para Borges «Um Aleph é um dos pontos do espaço que contém todos os pontos ». Assim « a anamorfose permite a Roussel traduzir uma dupla imagem do real : a primeira corresponde ao universo cotidiano, a segunda a um mundo imaginário em miniatura, espécie de espaço curvo regido por outro tipo de geometria ${ }^{62}$ (Ibid., p. 81 ).

$\mathrm{O}$ artigo desemboca em uma " programação preliminar »... E ao fato de que « a imaginação parece trabalhar permanentemente sobre uma exigência formal [...] geométrica ou linguística $»{ }^{63}$ (LEBORGNE, 2004, p. 87).

A anamorfose em Roussel é destacada por E. Leborgne em uma dimensão metafórica ; se sua intuição parece tocar em um dado da estrutura da obra não se trata contudo de uma verdadeira anamorfose que passa pelo procedimento geometral na perspectiva que encontraremos no Senhor L., um caso que nos foi encaminhado e que constrói um procedimento pautado em anamorfoses (L'HOMME..., 2010).

${ }^{60}$ No original : « l'extrême précision avec laquelle est décrite la courbure de l'espace sur la surface convexe des lunettes laisse penser que Roussel, avec son esprit systématique, est en train d'exposer un procédé poétique à part entière, dont l'origine reste mystérieuse » (LEBORGNE, 2004, p. 74). « une phrase métagrammatique qui nous ferait passer de l'espace réaliste de Courbet à l'espace courbé de Roussel, selon le procédé linguistique qu'il décrit dans son célèbre texte posthume? » (Ibid., p.74).

${ }^{61}$ No original: « cet exemple d'anamorphose montre la manière dont la libre association d'idées est strictement calquée sur le phénomène de l'optique : la pensée épouse le mouvement même du regard qui 'saute' d'un toit à un autre ». C'est le mélange de « rigueur géométrique et de carnavalisation burlesque » (Ibid., p. 74) « traits d'écriture », «à l'élaboration consciente d'un Procédé rousselien ».

${ }^{62}$ No original : « qui atteint [...] son apogée au moment où le monde physique est concentré en un point qui contiendrait symboliquement tout l'espace, à l'instar de l"aleph' de Borges » (LEBORGNE, 2004, p. 80). «Un Aleph est l'un des points de l'espace qui contient tous les points ». Ainsi « L'anamorphose permet à Roussel de traduire une double image du réel : la première correspond à l'univers quotidien, la seconde à un monde imaginaire en miniature, sorte d'espace courbe régi par un autre type de géométrie » (Ibid., p. 81).

${ }^{63}$ No original: « l'imagination semble travailler en permanence sous une contrainte formelle [...] géométrique ou linguistique » (LEBORGNE, 2004, p. 87) 


\section{De um momento epifânico à criação de anamorfose}

O Senhor L. considera que sua primeira anamorfose é a foto de sua família reunida em um ponto percebido na tampa de uma sopeira. " Tinha meu pai, minha mãe, Georgette ». Georgette, meia-irmã de sua mãe, cuidará dele e fará função de boa mãe e de governanta. Sua mãe não o amava.

Essa experiência focaliza algo da ordem de um fenômeno epifânico que vai colocá-lo a trabalhar : bricoler anamorfoses.

Lembremos que o termo epifania designa em J. Joyce um fenômeno que podemos qualificar, no discurso psiquiátrico, de fenômeno elementar, visto que ele escutava em seu meio fragmentos de diálogo aparentemente inofensivos mas que adquiriam para ele uma ressonância particular. Ele os registrava para guardar o traço, e foram para ele um bem precioso pois neles fundou a certeza de sua vocação de escritor.

A epifania toca na relação do corpo e da fala. Esse termo tomado da liturgia vale como traço de um acontecimento espiritual ou antes seu resíduo, pois o leitor não vê nele mais do que um incidente trivial. Não desenvolveremos aqui sobre a função da epifania para Joyce, mas podemos sublinhar a proximidade com a experiência do Senhor L.

O Senhor L. inicialmente elaborou esse dispositivo a partir do enigma sobre o que ele diz ter na cabeça, " essa estrutura profunda do cérebro ", " essa geometria ». Ele diz perseguir o dispositivo anamórfico desde a infância e ele «não exclui que seja o único » a elaborá-lo.

Assinala-se que quando ele utiliza o termo « geometria » já é para ele a tentativa de uma simbolização do fenômeno do qual ele não pode dizer mais nada. Quando ele declara que «é o único », ele precisa que não é o único a ter inventado a anamorfose, mas pressupõe que é o único a estabelecer uma relação entre essa construção anamórfica e a estrutura do fenômeno " geométrico de seu cérebro ».

Ele fez anamorfoses cilíndricas mas está fixado sobre as cônicas. O cone é lustrado, fazendo espelho. Para obter o efeito, o ponto de vista se situa no prolongamento do eixo passando pela extremidade do cone. A imagem anamórfica se desdobra ao redor da base sobre um suporte-plano horizontal. A imagem se forma assim, na ilusão de transparência, sobre o plano suporte coberto pela base do cone e se apresenta como uma imagem especular. Dito de outra maneira, em relação ao espectador ela se apresenta como invertida direita-esquerda : ao olho esquerdo do espectador corresponde o olho direito da imagem no espelho.

Mas, enquanto imagem anamórfica, ela se reflete sem essa inversão. A parte esquerda reflete a parte esquerda e a direita, a parte direita.

Por outro lado, há uma torção, a inversão do fora e do dentro. Por exemplo a superfície de um rosto é de fato a superfície que se situa na periferia, no exterior do desenho anamórfico. Essa inversão fora-dentro é evidente na imagem por causa da divisão das cores. 
$\mathrm{O}$ aparecimento anamórfico porta a presença inquietante da imagem do duplo, sinal de angústia na medida em que ela é, por essa mudança, o sinal da intervenção do objeto olhar como causa dessa inversão do Innenwelt e do Umwelt.

O sujeito é então tomado em uma oscilação entre $i(a)$ e $i \llbracket a)^{64}$ que remete à reversão freudiana da libido, como assinala Lacan no seminário sobre a Angústia : " Na oscilação econômica dessa libido reversível de $i(a)$ à $i[a)$, há algo, não que escapa, mas que intervém (...). A manifestação mais notável desse objeto $a$, o sinal de sua intervenção, é a angústia » ${ }^{65}$ (LACAN, 2004).

É a essa reversão da pulsão escópica que Lacan em $O$ objeto da psicanálise (L objet de la psychanalyse) (Id. 1965-66), aplica a estrutura de envelope da fantasia : o plano projetivo. Assim, o Senhor L., por meio de seu dispositivo anamórfico obtém uma variante da torção própria ao dispositivo da simulação do sinthome (Id., 2005, p. 118) de um Joyce ou de um Roussel.

\section{Uma escrita em espelho : o palíndromo no cone}

A aproximação é ainda mais evidente quando ele nos dá para decifrar uma escrita em espelho, páginas cobertas de palíndromos se inscrevendo na circunferência do cone.

Um palíndromo se lê nos dois sentidos de leitura, da esquerda à direita e da direita à esquerda. Assim, no exemplo dado pelo dicionário «Elu par cette crapule $»^{66}$. Notemos que as letras conservam sua orientação esquerda-direita, entretanto com a anamorfose a torção inverte, axialmente (cima-baixo) as letras conservando a leitura.

Há então uma amarração da letra e da imagem que faz valer o valor literal da função anamórfica.

O percurso que fizemos com esses três casos paradigmáticos - F. de Saussure, R. Roussel e Senhor L. - permitiu-nos testar a pertinência do conceito de suplência formulado por Lacan no seminário " O sinthome » (LACAN, 2005). Abordamo-lo pela topologia das superfícies, a torção da superfície unilateral equivalente à função do inconsciente, porque ela permite apreender com mais precisão o funcionamento de cada dispositivo, enquanto que a amarração borromeana, sem ser uma metalinguagem, aborda-a de imediato ao nível da generalização.

${ }^{64}$ i(a) conota a imagem do corpo próprio, o narcisismo primário, i'(a) conota a imagem especular. O objeto $a$ é o que na primeira imagem, não se projetando, está em falta na segunda : o lugar da falta que convoca objetos de desejo substitutivos.

${ }^{65}$ No original : «A l'oscillation économique de cette libido réversible de $i(a)$ à $i$ ( $(a)$, il y a quelque chose, non pas qui échappe, mais qui intervient (...). La manifestation la plus éclatante de cet objet $a$, le signal de son intervention, c'est l'angoisse » (LACAN, 2004).

${ }^{66}$ « Eleito por essa canalha» (N.T.). 
Essa suplência problematizada por Lacan e assim tematizada, teria permitido localizar, no campo da clínica, uma categoria distinta daquela do delírio que Freud considera, lembremos, como uma « tentativa de cura, uma reconstrução $»^{67}$ (FREUD, 1973, p. 315).

\section{Referências}

CARADEC, F. Raymond Roussel. Paris: Fayard, 1997.

FOUCAULT, M. Raymond Roussel. Paris: Gallimard, 1963.

FREUD, S. Remarques psychanalytiques sur l'autobiographie d'un cas de paranoïa: Dementia Paranoides. (Le président Schreber) In: Cinq psychanalyse. Paris: P.U.F., 1973.

GRANON-LAFONT J. Topologie lacanienne et clinique analytique. Point hors ligne. Paris: 1990.

GUIRAUD P. Les formes verbales de l'interprétation délirante. Annales Médico-Psychologiques, Ier semestre, p. 395-412, 1921.

L'HOMME aux anamorphoses. Communication au VIIè Congrès de l association mondiale de psychanalyse, Semblants et sinthome. Paris: 26-30 avril 2010.

LACAN J. D'une question préliminaire à tout traitement possible de la psychose. In: Écrits, Paris: Seuil, 1966. p. 531-583. . Løbjet de la psychanalyse - 1965-1966 (Inédit). . Le savoir du psychanalyste, leçon du 4 novembre 1971 (Inédit). . L'étourdit. In: Scilicet, 4, Paris: Seuil, 1973. . Le Séminaire Livre XX, Encore. Paris: Seuil, 1975. . Le Séminaire livre III, Les psychoses. Paris: Seuil, 1981. . Le séminaire Livre X, Langoisse. Paris: Seuil, 2004. Le séminaire, livre XXIII, Le sinthome. Paris: Seuil, 2005.

LEBORGNE, E. Le procédé de l'anamorphose dans les noces. La revue des lettres modernes. Paris-Caen: Minard, 2004.

LEW, R. La rhétorique de Raymond Roussel. Cahiers de lectures freudiennes. Le manque à lire, $\mathrm{n}^{\circ} 7 / 8$, Oct. 1985 .

MALEVAL, J.C. L'élaboration d'une suppléance par un procédé d'écriture: Raymond Roussel. In: Che vuoi ? n 19 , Sublimer ?, II. Chemin de la création. Paris: L’Harmattan, 2003.

${ }^{67}$ No original : « une tentative de guérison, une reconstruction » (FREUD, 1973, p. 315) 
MILNER, J.C. L Lamour de la langue. Paris: Seuil, 1978.

Le Périple structural, figures et paradigme. Paris: Seuil, 2002.

PELISSIER, Y. Traitement héroïque ! User avec la langue, ou langue-saignement Roussel, LUnebévue, n¹2, Printemps, EPEL, 1999.

ROUSSEL, R. Comment j ai écrit certains de mes livres. Paris: J.J. Pauvert, 1963a.

. Les Noces. t. V, Pierre Bazantay. Paris: Pauvert, $1963 \mathrm{~b}$.

. Nouvelles Impressions d Afrique. Paris: Al Dante / Léo Scheer, 2004.

. Impressions $d$ Afrique. Paris: Flammarion, 2005.

SAUSSURE, R. de. Cours de linguistique générale. Paris: Payot, 1972.

Écrits de linguistique générale. Paris: Gallimard, 2002.

STAROBINSKI, J. Les mots sous les mots. Les anagrammes de Ferdinand de Saussure. Paris: Gallimard, 1971.

\section{Agradecimento}

à Moussieur Olivier Douville, editor da revista Psychologie clinique, que gentilmente autorizou a publicação desta tradução. O artigo foi originalmente publicado naquele periódico, edição n. 34, 2012/2 - Création et Inconscient : le dire de l’ouvre. Éditeur : EDK, Groupe EDP Sciences. ISSN 1145-1882. http:// www.psycho-clinique.org/

Submissão em: 19/08/2013

Aceite em: 03/10/2013

Fabienne Hulak é Psicanalista, psicóloga clínica, membro da École de la Cause Freudienne e da Associação Mundial de Psicanálise,

Maître de Conférences no Département de Psychanalyse, Université de Paris VIII. Laboratoire de recherche EA 4007.

Endereço para correspondência: 250 Boulevard Raspail, 75014 Paris, France. E-mail: hulak.fabienne@,wanadoo.fr

Leticia Vier Machado é Psicóloga, graduada pela Universidade Estadual de Maringá, e mestranda em Psicologia pela Universidade Federal de Santa Catarina - bolsista CAPES. Realizou mobilidade acadêmica na Université Lumière Lyon 2, França. E-mail: leticiaviermachado@gmail.com 